\title{
Visuo-spatial neglect: qualitative differences and laterality of cerebral lesion
}

\author{
Peter W Halligan, John P Burn, John C Marshall, Derick T Wade
}

\begin{abstract}
From a large sample of patients who sustained a first stroke, 98 patients were selected with unilateral left brain damage and 92 with unilateral right brain damage. Examined on a visual search task (Star Cancellation) approximately four years after onset, we found a comparable incidence of visual inattention in the two groups. Despite this quantitative similarity, the qualitative pattern of performance was different in the two impaired samples. Patients with right brain damage showed a distinctive linear relationship whereby omission errors increased from right to left across the stimulus page. Within the left brain damaged sample, two subgroups could be discerned. As expected, one subgroup showed more contralesional than ipsilesional errors, but the other subgroup was comparable to the sample with right hemisphere damage. The reasons are discussed for these qualitative differences, drawing particular attention to the importance of motor/ manual factors in the determination of performance on visual search tasks.
\end{abstract}

(F Neurol Neurosurg Psychiatry 1992;55:1060-1068)

Most studies of visual neglect report that the condition is more frequent and more severe after right than left hemisphere lesions. ${ }^{12}$ This asymmetry has led to several hypotheses about hemispheric specialisation for perceptuoattentional processes.

Kinsbourne $^{3}$ has argued that activational imbalance produced by a hemispheric lesion determines the directional vector that controls attentional orientating. Central to Kinsbourne's model is the assumption of two mutually antagonistic vectors which direct attention to opposite sides of space; selective arousal of each hemisphere thus results in enhanced attention to contralateral space. Left hemisphere disinhibition after right hemisphere damage leaves the strong rightward orienting tendency of the intact hemisphere unopposed and results in left sided neglect. Left sided bias after lesions of the left hemisphere is inherently weaker and consequently leads to a directional neglect of lesser severity. ${ }^{4}$

A related hypothesis proposes that the right hemisphere is dominant for the deployment of attention to all spatial locales; "attentional neurons" in the right cerebral hemisphere have bilateral receptive fields while those in the left hemisphere are exclusively concerned with contralateral space. ${ }^{6}$ Consequently, damage to the right hemisphere should result not only in contralesional neglect but also some degree of neglect for ipsilateral space; ${ }^{6-9}$ the left hemisphere requires assistance from the right hemisphere to attend fully to right sided space. By contrast, damage to the left hemisphere should result in relatively mild contralesional neglect. ${ }^{9}$ Recently, Gainotti et al $^{10}$ questioned this position. They suggest, as did Albert, ${ }^{11}$ that ipsilateral omissions on visual search tasks after right hemisphere damage result from a generalised lowering of attention; as such they are not theoretically related to omissions on the contralesional side of space.

Other studies of neglect have reported a qualitative difference in performance after left and right brain damage. ${ }^{1213}$ Gainotti et al ${ }^{1415}$ maintain that visual neglect after right hemisphere damage is characterised by an inability to extract information from the left half of a visual stimulus during single fixations. By contrast, conscious scanning in visual search tasks that involve the full exploration of extrapersonal space is, they claim, equally impaired after right or left hemisphere lesions. Gainotti et $a l^{16}$ employed a task that required explicit saccadic eye movements; patients searched for pictures of animals within a complex visual array. No significant difference was found between the total number of patients with left and right brain damage who showed contralesional neglect on this task. However, when the same patients carried out a task which required the extraction of information from single fixations (an overlapping figures task), the right hemisphere patients were significantly more impaired than the left hemisphere patients.

This equivalence in performance between left and right brain damaged patients on visual search tasks described by Gainotti et al ${ }^{16}$ has not always been found. Indeed, most studies report that right brain damaged patients omit significantly more targets than left brain damaged patients on tasks that require explicit scanning. ${ }^{91718}$ Furthermore, a study of 91 right brain damaged patients and 40 nonaphasic left brain damaged patients by Egelko et $a l^{19}$ used a task which required the analysis of lateralised fine details during fixations and found that this type of deficit was not unique to right brain damaged patients. An examination of the test materials and response modes used in these studies suggests reasons for the difference in results. Unlike the study of Egelko et al, which required a verbal response, the study of 
Table 1 Characteristics of control sample

\begin{tabular}{llllll}
\hline & Age Band & Number & Mean age & Sex M/F & $\begin{array}{l}\text { Star Cancellation test } \\
\text { Mean score }\end{array}$ \\
\hline 1 & $50-55$ & 17 & $52 \cdot 4$ & $12 / 5$ & $53 \cdot 6$ \\
2 & $56-60$ & 14 & $58 \cdot 2$ & $3 / 11$ & $53 \cdot 6$ \\
3 & $61-65$ & 38 & $63 \cdot 1$ & $22 / 16$ & $53 \cdot 5$ \\
4 & $66-70$ & 50 & $67 \cdot 7$ & $26 / 24$ & $52 \cdot 9$ \\
5 & $71-75$ & 32 & $72 \cdot 4$ & $17 / 15$ & $52 \cdot 4$ \\
\hline
\end{tabular}

Gainotti et al required an explicit manual response. The presence of a motor response may have been responsible for the behavioural dissociation between RBD and LBD groups.

Our study is a contribution to some of these controversies. We investigate the quantitative and qualitative performance of stroke patients with unilateral left and right hemisphere damage on a visual search task and examine the relationship between ipsilateral and contralesional omissions in those groups.

\section{EXPERIMENT 1}

Subjects

A normative sample of 151 volunteer subjects, mean (SD) age $64.9(6.3)$ years; with an age range of 50-75 years was recruited from community general practitioner clinics and voluntary service groups. All subjects were free from serious disease and had no history of brain injury. They were 80 men (mean age $64 \cdot 8$ ) and 71 women (mean age $65 \cdot 1$ ), divided into five age bands, as shown in table 1 .

\section{Materials and Method}

Each subject was administered the Star Cancellation Task (SCT) from the Behavioural Inattention Test. ${ }^{20} \mathrm{~A}$ previous study ${ }^{21}$ found the SCT to be a sensitive measure of visual neglect. The test consists of 52 large stars, 13 randomly positioned letters and 10 short words interspersed with 56 smaller stars that are the target stimuli. The overall dimensions of the test are $298 \times 208 \mathrm{~mm}$ and the stimulus page is centred on the subjects' midsagittal plane. The task is to locate and cross out (cancel) all the small stars. Centrally located small stars are crossed out by the examiner to illustrate the requirements of the test. For

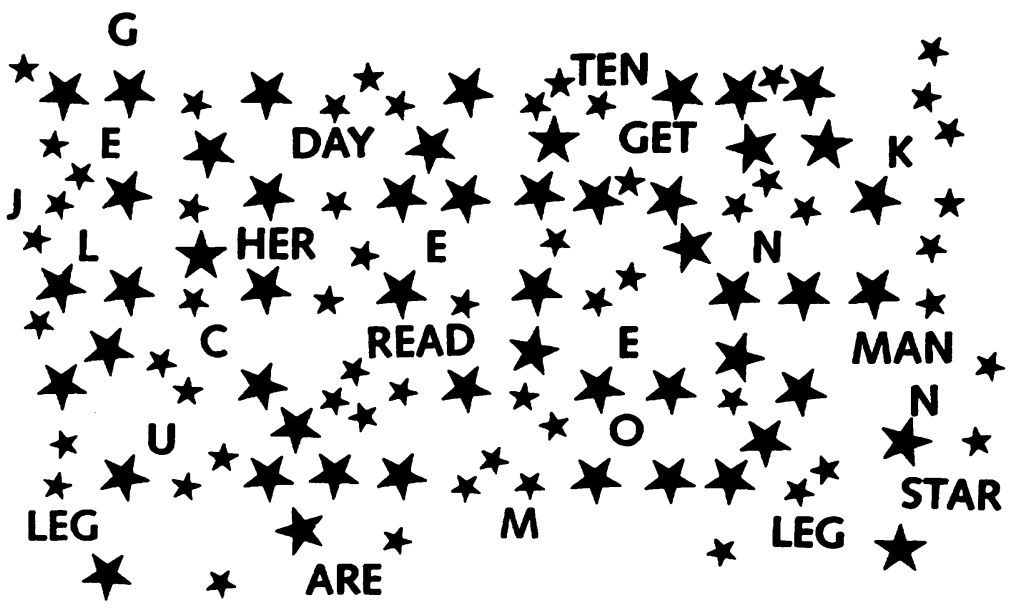

Figure 1 Star Cancellation test (reproduced by permission of Thames Valley Test Company). scoring purposes, the SCT stimulus sheet can be divided into six columns, three left and three right, and the overall score is out of a total of 54. A copy of the test is shown in fig. 1.

Each subject was seated approximately 455 $\mathrm{mm}$ from the stimulus sheet. Task instructions were explained and demonstrated. Controls used their right hand. Head and eye movements were in no way restricted, but moving the stimulus sheet was not permitted The subject's attention was initially drawn to the centre of the sheet in so far as the investigator demonstrated cancellations located there. No time limit was imposed.

\section{Results}

The performance of the control subjects is shown in table 1 . There were no significant differences between the sexes on the SCT mean score $(t=-0.81, d f=134, n s)$. There is, however, a clear fall off in performance with increasing age; the correlation with age was $r=$ $-0.33(\mathrm{p}<0.001)$, although in quantitative terms the effect was very small (an overall mean difference of 1.2 omissions between 50-55 year olds and 71-75 year olds). As a group, control subjects omitted less than $2 \%$ of targets. There was no statistically significant difference between the percentage of errors made on the left (columns one to three) and the right (columns four to six): left $=42 \%$; right $=58 \%$.

\section{EXPERIMENT 2}

Patient sample:

Chronic stroke patients with unilateral left and right brain damage were examined. The sample was drawn from the Oxfordshire Community Stroke Project (OCSP) and has been fully described elsewhere. ${ }^{22}$ In summary, this project assessed the incidence and outcome of first-ever stroke in a population of 105000 people registered with ten general practices in Oxfordshire. The register of patients began on 1 November 1982 and continued until 1 October 1986. Each patient was seen as soon as possible by a neurologist attached to the study who took a standard neurological history, made the clinical examination and reviewed the patient's medical records for evidence of previous cerebrovascular events. Clinical diagnosis of stroke was based on criteria set out by the World Health Organization. ${ }^{23}$ Patients were only included in the study if they presented with a clinically apparent first-ever stroke. The study also obtained CT evidence where possible. In most cases, CT was performed within 28 days of the onset of clinical symptoms. All scans were interpreted by a neuroradiologist blind to the patients' diagnosis. For cases without CT, the Guy's Hospital Stroke Diagnostic Score was used to determine whether the stroke was due to haemorrhage or infarction. ${ }^{24} \mathrm{~A}$ standardised assessment of visuo-spatial neglect was not included at this stage.

Of the 1306 patients notified to the study with suspected stroke, 675 were considered to 
have a first-ever stroke. CT scans were performed in $80 \%$ of these cases. All surviving cases were then followed prospectively in their place of residence by research nurses at one month, six months, 12 months and then annually. This follow up included a standardised questionnaire to detect recurrent cerebrovascular events. In 1988, two years after the completion of the stroke register, a final follow up of survivors was started. At this stage the Star Cancellation Test (SCT) was included in a revised battery of measures to evaluate residual impairments, handicap and disability.

\section{Scoring of the SCT and patient characteristics}

As the mean age of the patient sample was older than that of the oldest control, we allowed for further fall-off with age. The mean fall-off between each of the age bands 61-65, $66-70$ and $71-75$ is approximately 0.5 points. If this is extended to cover the age bands $76-80,81-85,86-90$ and 91-95, one would expect an additional fall-off of up to two points. Consequently, the criterion of the lowest score less one obtained by any control (that is, 46) drops to 44. Accordingly, we choose to define visual inattention as any score greater than ten omissions. This cut-off (44) is three points less than the worst score obtained by any control in the 50-70 year old age range. As all patients were selected for unilateral brain damage, no account was taken at this stage of the spatial distribution of omissions; that is, patients were not preselected on the basis of more contralesional than ipsilesional omissions.

Of the total of 675 first-ever strokes, 328 (48\%) survived to follow up. Twenty five patients were not tested. Of the remaining 303 a further 113 were excluded for one or more of the following reasons; brain stem lesions; recurrent strokes on the opposite side; left handedness or very poor visual acuity. Of the 190 patients remaining, 98 had left and 92 right brain damage. Of the 98 patients with left brain damage, 12 showed visual inattention on the criterion for Star cancellation described above; of the 92 patients with right brain damage, 14 showed visual inattention. The final clinical sample thus comprised 26 righthanded patients; 14 with right brain damage patients and 12 with left brain damage. Patients were also evaluated for the presence of widespread mental deterioration using the Hodkinson Mental Test, ${ }^{25}$ and overall functional ability using the Barthel ADL Index. ${ }^{26}$

The 12 left brain damaged patients (LBD) had a mean (SD) age of $78 \cdot 1(10 \cdot 8)$ and were on average (SD) 230 weeks (79.8) post stroke, with a range of 95 to 337 weeks. There were six males and six females. At follow up, none of the 12 patients demonstrated visual field deficits to confrontation. The 14 right brain damaged patients (RBD) had a mean (SD) age of $76.9(8.9)$ and were on average 202 weeks post stroke, $(66.4)$ with a range of 116-324 weeks. There were six men and eight women. Five of the fourteen showed left hemianopia, five visual extinction, two had normal fields and two could not be assessed. The incidence of visual field deficits/extinction is significantly different in the two groups (Chi square $=5.33$, $\mathrm{p}<0.05)$.

\section{Materials and Procedure}

Patients were administered the Star Cancellation Task (SCT) in the same way as controls. As left visuo-spatial neglect is often associated with left hemiparesis, traditional assessment assumes the use of the patient's (dominant) right hand. In the RBD group all patients used their right (ipsilesional) hand. Since all the LBD patients were right handed and only one of the 12 had a mild right handed hemiparesis all of these patients likewise used their (contralesional) right hand to perform the task.

\section{Results \\ Patients}

The two patient groups did not differ significantly in age $(t=-0 \cdot 29, d f=22)$; number of weeks post onset $(t=0.96, d f=22)$, Barthel score $(t=-1 \cdot 19, \mathrm{df}=23)$ or Hodkinson Mental Test $(t=0.68, d f=23)$. Scores on the Barthel Index correlated significantly with errors on the SCT: RBD, $\mathrm{r}=-0.81, \mathrm{p}<$ 0.001 ; LBD, $r=-0.54, p<0.05$. Scores on the Hodkinson correlated significantly with errors on the SCT: RBD r $=-0.66, \mathrm{p}<0.01$ and LBD $r=-0.60, p<0.05$. Patient details

Table 2 RBD patients characteristics and performance on the SCT

\begin{tabular}{|c|c|c|c|c|c|c|c|c|c|}
\hline Number & Age & Sex & $\begin{array}{l}\text { Visual } \\
\text { Fields }\end{array}$ & $\begin{array}{l}\text { Hodkinson' } \\
\text { Score }\end{array}$ & $\begin{array}{l}\text { Weeks } \\
\text { Post }\end{array}$ & $\begin{array}{l}\text { Barthel } \\
\text { Score }\end{array}$ & $\begin{array}{l}\text { Lesion } \\
\text { Location }\end{array}$ & $\begin{array}{l}\text { SCT } \\
\text { Score }\end{array}$ & $\begin{array}{l}\text { Laterality } \\
\text { Index }\end{array}$ \\
\hline $\begin{array}{r}1 \\
2 \\
3 \\
4 \\
5 \\
6 \\
7 \\
8 \\
9 \\
10 \\
11 \\
12 \\
13 \\
14\end{array}$ & $\begin{array}{l}87 \\
82 \\
73 \\
75 \\
57 \\
66 \\
81 \\
87 \\
82 \\
89 \\
73 \\
78 \\
79 \\
68\end{array}$ & $\begin{array}{l}\mathbf{F} \\
\mathbf{F} \\
\mathbf{M} \\
\mathbf{F} \\
\mathbf{M} \\
\mathbf{F} \\
\mathbf{M} \\
\mathbf{M} \\
\mathbf{F} \\
\mathbf{F} \\
\mathbf{F} \\
\mathbf{F} \\
\mathbf{M} \\
\mathbf{M}\end{array}$ & $\begin{array}{l}\text { N/A } \\
\text { LH } \\
\text { LH } \\
\text { LH } \\
\text { L.Ext } \\
\text { L.Ext } \\
\text { L.Ext } \\
\text { L.Ext } \\
\text { LH } \\
\text { NF } \\
\text { N/A } \\
\text { NF } \\
\text { L.Ext } \\
\text { LH }\end{array}$ & $\begin{array}{r}1 \\
4 \\
7 \\
3 \\
2 \\
9 \\
9 \\
3 \\
10 \\
9 \\
5 \\
8 \\
8 \\
10\end{array}$ & $\begin{array}{l}220 \\
324 \\
207 \\
262 \\
141 \\
160 \\
310 \\
205 \\
220 \\
216 \\
105 \\
139 \\
208 \\
116\end{array}$ & $\begin{array}{r}6 \\
7 \\
9 \\
6 \\
13 \\
4 \\
14 \\
6 \\
20 \\
16 \\
19 \\
17 \\
18 \\
13\end{array}$ & $\begin{array}{l}\text { F } \\
\text { FP } \\
\text { FP } \\
\text { FPIC } \\
\text { FPBG } \\
\text { FPT } \\
\text { FPT } \\
\text { FPT } \\
\text { NS } \\
\text { ICBG } \\
\text { TP } \\
\text { ICBG } \\
\text { ICBG } \\
\text { TICBG }\end{array}$ & $\begin{array}{l}47 \\
43 \\
41 \\
40 \\
30 \\
30 \\
29 \\
29 \\
16 \\
15 \\
15 \\
13 \\
12 \\
12\end{array}$ & $\begin{array}{l}0.00 \\
0.00 \\
0.00 \\
0.00 \\
0.38 \\
0.12 \\
0.32 \\
0.20 \\
0.39 \\
0.48 \\
0.51 \\
0.46 \\
0.40 \\
0.47\end{array}$ \\
\hline $\begin{array}{l}\text { Mean } \\
\text { SD }\end{array}$ & $\begin{array}{l}76.9 \\
8 \cdot 9\end{array}$ & & & $\begin{array}{l}6 \cdot 3 \\
3 \cdot 2\end{array}$ & $\begin{array}{l}202 \cdot 4 \\
66 \cdot 4\end{array}$ & $\begin{array}{r}12.0 \\
5.6\end{array}$ & & $\begin{array}{l}26 \cdot 6 \\
12.7\end{array}$ & $\begin{array}{l}0.27 \\
0.20\end{array}$ \\
\hline
\end{tabular}

Male $=M /$ Female $=F ;$ NF $=$ Normal fields $; / A=$ Not assessed $; F=$ Frontal $;$ LH $=$ Left homonomous hemianopia $T=$ Temporal; L.Ext. = Left sided extinction; $\mathbf{P}=$ Parietal; Barthel Score (out of 20); BG = Basal Ganglia; SCT = Star cancellation score (omissions); IC = Internal capsule; NS = Negative scan. 
Table 3 LBD patients characteristics and performance on the SCT

\begin{tabular}{|c|c|c|c|c|c|c|c|c|c|}
\hline Number & Age & Sex & $\begin{array}{l}\text { Visual } \\
\text { Fields }\end{array}$ & $\begin{array}{l}\text { Hodkinson' } \\
\text { Score }\end{array}$ & $\begin{array}{l}\text { Weeks } \\
\text { Post }\end{array}$ & $\begin{array}{l}\text { Barthel } \\
\text { Score }\end{array}$ & $\begin{array}{l}\text { Lesion } \\
\text { Location }\end{array}$ & $\begin{array}{l}\text { SCT } \\
\text { Score }\end{array}$ & $\begin{array}{l}\text { Laterality } \\
\text { Index }\end{array}$ \\
\hline $\begin{array}{r}1 \\
2 \\
3 \\
4 \\
5 \\
6 \\
7 \\
8 \\
9 \\
10 \\
11 \\
12\end{array}$ & $\begin{array}{l}79 \\
89 \\
79 \\
98 \\
67 \\
80 \\
74 \\
85 \\
64 \\
61 \\
87 \\
74\end{array}$ & $\begin{array}{l}M \\
F \\
F \\
F \\
M \\
F \\
F \\
F \\
M \\
M \\
M \\
M\end{array}$ & $\begin{array}{l}\text { NF } \\
\text { NF } \\
\text { NF } \\
\text { NF } \\
\text { NF } \\
\text { NF } \\
\text { NF } \\
\text { R.Ext } \\
\text { NF } \\
\text { NF } \\
\text { N/A } \\
\text { NF }\end{array}$ & $\begin{array}{l}1 \\
1 \\
9 \\
0 \\
5 \\
4 \\
7 \\
8 \\
9 \\
8 \\
6 \\
7\end{array}$ & $\begin{array}{r}138 \\
208 \\
267 \\
111 \\
263 \\
312 \\
262 \\
232 \\
337 \\
223 \\
95 \\
314\end{array}$ & $\begin{array}{r}4 \\
11 \\
20 \\
10 \\
17 \\
8 \\
16 \\
20 \\
20 \\
20 \\
10 \\
20\end{array}$ & $\begin{array}{l}\text { F } \\
\text { NS } \\
\text { F } \\
\text { P } \\
\text { F } \\
\text { T } \\
\text { NS } \\
- \text { NS } \\
\text { IC } \\
\text { FPICBG } \\
\text { T }\end{array}$ & $\begin{array}{l}47 \\
35 \\
32 \\
24 \\
22 \\
17 \\
17 \\
16 \\
12 \\
11 \\
10 \\
10\end{array}$ & $\begin{array}{l}1.0 \\
0.42 \\
0.59 \\
0.56 \\
0.47 \\
0.54 \\
0.59 \\
0.55 \\
0.45 \\
0.44 \\
0.52 \\
0.59\end{array}$ \\
\hline $\begin{array}{l}\text { Mean } \\
\text { SD }\end{array}$ & $\begin{array}{l}78 \cdot 1 \\
10 \cdot 8\end{array}$ & & & $\begin{array}{l}5 \cdot 3 \\
3 \cdot 0\end{array}$ & $\begin{array}{r}230 \cdot 2 \\
79 \cdot 8\end{array}$ & $\begin{array}{r}14 \cdot 7 \\
5 \cdot 7\end{array}$ & & $\begin{array}{l}21 \cdot 1 \\
11 \cdot 6\end{array}$ & $\begin{array}{l}0.56 \\
0.15\end{array}$ \\
\hline
\end{tabular}

Male $=M /$ Female $=F ; N F=$ Normal fields $; / A=$ Not assessable; $F=$ Frontal $; H=$ Left homonomous hemianopia; $T=$ Temporal $;$ R.Ext. = Reft sided extinction; P = Parietal; Barthel Score (out of 20); BG = Basal Ganglia; SCT = Star cancellation score; IC = Internal capsule; NS = Negative scan; $-=$ no scan.

and performance are shown in tables 2 (RBD) and 3 (LBD) with patients ranked according to their total error score. Patient 1 in table 2 and Patient 3 in table 3 had sustained haemorrhages; all other patients had infarcts.

\section{Analysis of Total Omissions}

In terms of total score on the SCT, there was no significant difference between left and right brain damaged groups $(t=1 \cdot 15, \mathrm{df}=23)$. In the RBD group, the total number of omissions was positively related to the number of days after onset $(r=0.54, p<0.05)$. In these patients, more severe neglect was observed for

Table 4 Percentage errors for each column per patient in the RBD group on the SCT

\begin{tabular}{|c|c|c|c|c|c|c|c|}
\hline \multirow[b]{2}{*}{ Patients } & \multicolumn{3}{|l|}{ Left } & \multicolumn{3}{|l|}{ Right } & \multirow[b]{2}{*}{ Mean \% } \\
\hline & Column 1 & Column 2 & $\overline{\text { Column } 3}$ & Column 4 & Column 5 & Column 6 & \\
\hline $\begin{array}{r}1 \\
2 \\
3 \\
4 \\
5 \\
6 \\
7 \\
8 \\
9 \\
10 \\
11 \\
12 \\
13 \\
14\end{array}$ & $\begin{array}{l}100 \\
100 \\
100 \\
100 \\
100 \\
100 \\
100 \\
100 \\
38 \\
63 \\
38 \\
38 \\
63 \\
13\end{array}$ & $\begin{array}{r}100 \\
100 \\
100 \\
100 \\
100 \\
100 \\
75 \\
88 \\
38 \\
13 \\
13 \\
25 \\
63 \\
25\end{array}$ & $\begin{array}{r}100 \\
100 \\
100 \\
100 \\
18 \\
73 \\
45 \\
64 \\
55 \\
18 \\
27 \\
27 \\
0 \\
36\end{array}$ & $\begin{array}{r}100 \\
82 \\
100 \\
91 \\
36 \\
36 \\
45 \\
45 \\
27 \\
27 \\
27 \\
9 \\
18 \\
18\end{array}$ & $\begin{array}{r}63 \\
63 \\
38 \\
25 \\
50 \\
25 \\
38 \\
25 \\
13 \\
13 \\
50 \\
25 \\
0 \\
38\end{array}$ & $\begin{array}{r}50 \\
25 \\
0 \\
13 \\
50 \\
0 \\
25 \\
0 \\
0 \\
38 \\
13 \\
25 \\
0 \\
0\end{array}$ & $\begin{array}{l}86 \\
78 \\
73 \\
72 \\
59 \\
56 \\
55 \\
54 \\
29 \\
29 \\
28 \\
25 \\
24 \\
22\end{array}$ \\
\hline $\begin{array}{l}\text { Mean } \\
\text { SD } \\
\text { Range }\end{array}$ & $\begin{array}{c}75 \cdot 2 \\
31 \cdot 9 \\
13-100\end{array}$ & $\begin{array}{c}67 \cdot 1 \\
36 \cdot 4 \\
13-100\end{array}$ & $\begin{array}{r}54 \cdot 5 \\
35 \cdot 4 \\
0-100\end{array}$ & $\begin{array}{c}47 \cdot 2 \\
32 \cdot 1 \\
9-100\end{array}$ & $\begin{array}{l}33 \cdot 3 \\
18 \cdot 8 \\
0-63\end{array}$ & $\begin{array}{l}17 \cdot 1 \\
18 \cdot 7 \\
0-50\end{array}$ & $\begin{array}{l}49 \cdot 3 \\
22 \cdot 6 \\
22-86\end{array}$ \\
\hline
\end{tabular}

Table 5 Percentage errors for each column per patient in the LBD group on the SCT

\begin{tabular}{|c|c|c|c|c|c|c|c|}
\hline \multirow[b]{2}{*}{ Patients } & \multicolumn{3}{|l|}{ Left } & \multicolumn{3}{|l|}{ Right } & \multirow[b]{2}{*}{ Mean \% } \\
\hline & Column 1 & Column 2 & Column 3 & Column 4 & Column 5 & Column 6 & \\
\hline $\begin{array}{r}1 \\
2 \\
3 \\
4 \\
5 \\
6 \\
7 \\
8 \\
9 \\
10 \\
11 \\
12\end{array}$ & $\begin{array}{r}13 \\
38 \\
38 \\
50 \\
88 \\
13 \\
25 \\
50 \\
63 \\
63 \\
25 \\
0\end{array}$ & $\begin{array}{r}100 \\
88 \\
75 \\
25 \\
50 \\
38 \\
38 \\
0 \\
25 \\
13 \\
13 \\
13\end{array}$ & $\begin{array}{r}100 \\
82 \\
55 \\
36 \\
36 \\
27 \\
0 \\
18 \\
9 \\
18 \\
9 \\
0\end{array}$ & $\begin{array}{r}100 \\
73 \\
73 \\
45 \\
36 \\
0 \\
55 \\
27 \\
18 \\
0 \\
0 \\
36\end{array}$ & $\begin{array}{r}100 \\
63 \\
25 \\
25 \\
25 \\
25 \\
25 \\
13 \\
13 \\
13 \\
13 \\
50\end{array}$ & $\begin{array}{r}100 \\
25 \\
100 \\
88 \\
13 \\
100 \\
50 \\
75 \\
13 \\
25 \\
63 \\
13\end{array}$ & $\begin{array}{l}86 \\
62 \\
61 \\
45 \\
41 \\
34 \\
32 \\
31 \\
24 \\
22 \\
21 \\
19\end{array}$ \\
\hline $\begin{array}{l}\text { Mean } \\
\text { SD } \\
\text { Range }\end{array}$ & $\begin{array}{l}38 \cdot 8 \\
25 \cdot 3 \\
0-88\end{array}$ & $\begin{array}{c}39 \cdot 8 \\
32 \cdot 3 \\
0-100\end{array}$ & $\begin{array}{c}32.5 \\
31.9 \\
0-100\end{array}$ & $\begin{array}{c}38 \cdot 6 \\
32 \cdot 3 \\
0-100\end{array}$ & $\begin{array}{c}32 \cdot 5 \\
26 \cdot 3 \\
13-100\end{array}$ & $\begin{array}{c}55 \cdot 4 \\
36 \cdot 6 \\
13-100\end{array}$ & $\begin{array}{l}39 \cdot 8 \\
20 \cdot 5 \\
19-86\end{array}$ \\
\hline
\end{tabular}

patients carrying out the test later after onset. In the LBD group, there was no significant relationship between total SCT score and time after onset $(r=-0.33)$.

\section{Spatial Location of Omissions}

The raw data for the two patient groups can also be described in terms of the mean omissions across the six columns of the SCT. To examine individual variability within the two clinical groups, each patient's columnar position (CP) score as a percentage of the total number of targets per column was calculated (tables 4 and 5).

Assuming an interval scale of measurement, the performance of the RBD group (table 4) has a distinctive linear presentation. The mean (SD) fall-off from column to column (right to left) is $11.6 \%(3.8)$. The mean within subject correlation between columns and omissions is $r=-0.69(p<0.01)$.

By contrast, the performance of the LBD group (table 5) across the six columns shows little consistent variation. There is a nonsignificant linear correlation of $r=0.10$ between error rate and column position. The percentage of omissions for both patient groups is shown graphically in figs 2 (RBD) and 3 (LBD). Although there was no significant difference in the total errors made by LBD and RBD patients, there was clearly a qualitative distinction between groups.

\section{Case Analysis}

Tables 4 and 5 show that the performance of individual patients across columns is characterised by a series of plateaux and jumps ranging from 0 to $100 \%$ omissions. If the position of each patient's maximum positive discontinuity is plotted as a function of the pair of columns between which that gap is found, it can be seen that the magnitude of visual neglect is not intrinsically linked to the midsagittal plane. ${ }^{27}$

The performance of individual patients can also be analysed as a function of error percentage per column. In the RBD group, eight patients $(57 \%)$ show significant linear relationships between column position and omission rate. The remaining six patients show no obvious pattern. Six of the eight patients who showed a linear presentation had parietal 


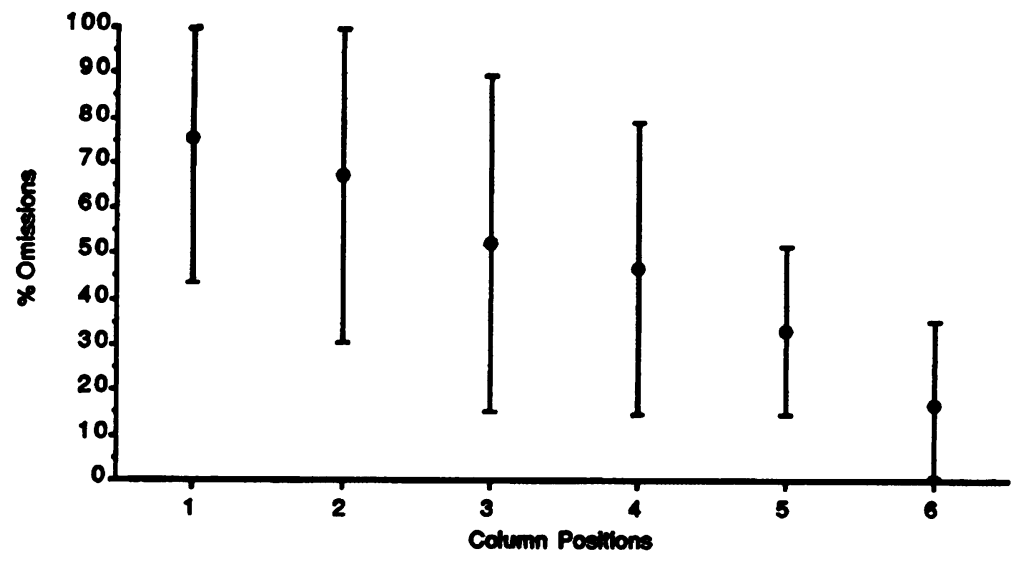

Figure 2 Mean and standard deviations across columns for right brain damaged patients on star cancellation.

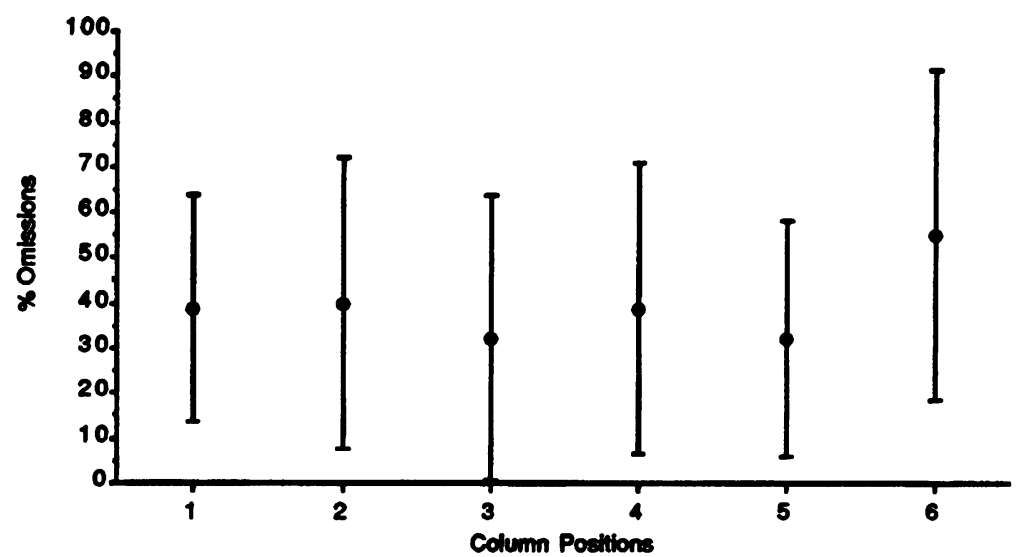

Figure 3 Mean and standard deviations across columns for left brain damaged patients on star cancellation.
Number of ipsilesional and contralesional omissions on the SCT

In the sample of Gainotti et $a,^{10} 34$ of the RBD patients (33\%) showed contralesional and 24 (23\%) ipsilesional inattention. In their LBD sample, six patients (5\%) showed contralesional and 19 (15\%) ipsilesional inattention. Post hoc comparisons revealed that contralesional omissions were significantly greater after right than left brain damage. No difference was found between the two groups for ipsilesional omissions.

To investigate this association between ipsilesional and contralesional omissions, Gainotti et $\mathrm{al}^{1015}$ point out that it is useful to restrict analysis to the lateral extents of the test stimulus so as to avoid misclassifying contralesional omissions that may extend beyond the patient's sagittal midline. Accordingly, our analysis considered only those omissions lying in the outer columns of the SCT, that is, columns one and two (left) and five and six (right). The data were submitted to a two-way (repeated) ANOVA with two main factors: (a) hemispheric side of lesion (RBD/LBD), and (b) side of SCT page (ipsilateral/contralateral). The mean number of omissions from the respective contralesional and ipsilesional sides of the test sheet were calculated and are shown together with the results of the ANOVA in table 6 .

There are significant effects for both main factors and their interaction. Post-hoc comparisons showed that: (a) contralesional omissions were significantly greater in RBD than in LBD patients; (b) no significant difference was observed between the two groups in ipsilesional space; (c) within the RBD group, omissions on the contralesional side were significantly greater than those on the ipsilesional side; (d) within the LBD group, there was no significant difference between contralesional and ipsilesional omissions.

In addition to comparing the overall numbers of contralesional and ipsilesional omissions, their relative proportions in individual patients must be calculated. The assumption is that most RBD patients will show an error bias to the left and the LBD an error bias to the right. Gainotti et al $^{10}$ found that of $43 \mathrm{RBD}$ patients classified as showing inattention, 19 (44\%) showed only contralesional omissions, $15(35 \%)$ showed both contralesional and ipsilesional and nine $(21 \%)$ patients showed ipsilesional omissions only. Although complete data were not supplied for the LBD patients it is likely that these patients could also be divided into similar groups.

To obtain a measure of lateral bias, a ratio index was calculated using a method described by Friedman. ${ }^{28}$ The number of stars successfully cancelled in the three left sided columns is divided by the total number of stars cancelled. In the RBD group, values between 0.00 and 0.49 indicate the extent of left (contralesional) bias; scores of 0.50 indicate no bias; while values between 0.51 and 1.0 indicate the extent of right (ipsilesional) bias. In the RBD group, only 1 patient (No 11 ), with relatively 
Figure 4 Mean column performance together with regression line for; a) right brain damaged patients with contralesional damaged patients with ipsilesional omissions; c) left brain damaged patients with contralesional omissions. omissions; b) left brain

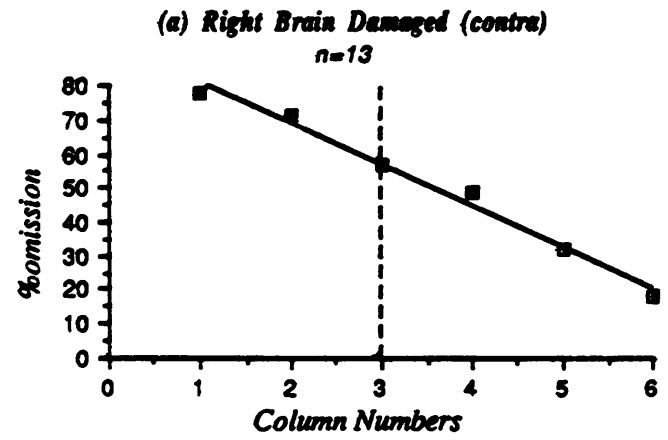

(b) Left Brain Dameged (ipsi) $n=4$

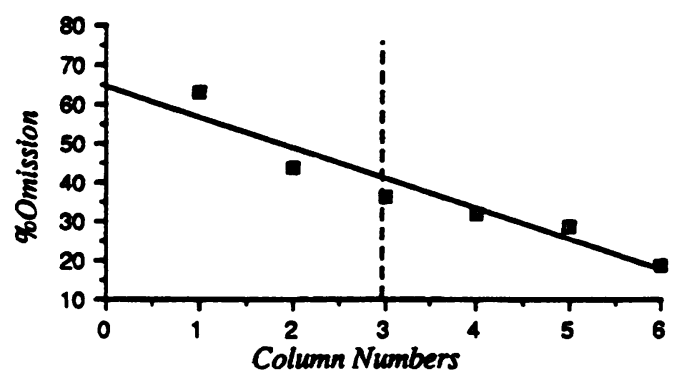

(c) Left Brein Demeged(contra) $n=8$

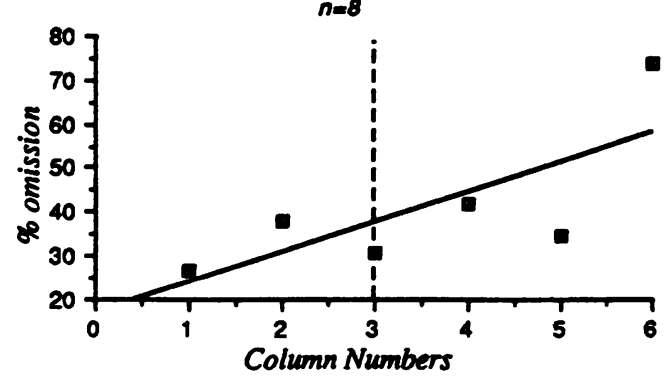

mild neglect, showed more omissions on the ipsilesional side. Ratio scores for the RBD patients are shown in table 2 . In the LBD group, values between 0.00 and 0.49 indicate the extent of left (ipsilesional) bias; scores of 0.50 indicate no bias; while values between 0.51 and 1.0 indicate the extent of right (contralesional) bias. In the LBD group, four patients (Nos 2,5,9 and 10) showed more errors on the ipsilateral side. Ratio scores for the LBD patients can be found in table 3.

Each of the groups can thus be divided into "contralesional" and "ipsilesional" subgroups. There were no patients whose score fell below the control cut-off who did not also show a

Table 7 Association between Lateralised omissions on the SCT for LBD/RBD patients and non-specific variables

\begin{tabular}{llll}
\hline & Age & Hodkinson & Barthel \\
\hline$R B D$ & & & \\
Contralesional & -0.08 & $-0.58^{\mathrm{c}}$ & $-0.79^{\mathrm{a}}$ \\
Ipsilesional & -0.18 & $-0.62^{\mathrm{b}}$ & -0.23 \\
LBD & & & \\
Contralesional & 0.52 & -0.51 & $-0.67^{\mathrm{b}}$ \\
Ipsilesional & -0.12 & -0.29 & -0.13 \\
\hline
\end{tabular}

$a=p<0.001 ; b=p<0.02 ; c=p<0.05$. lateralised score. Given the small size of the RBD ipsilesional group $(N=1)$ only the other three subgroups will be considered. Performance of the "contralesional" RBD group ( $n=$ 13) shows a distinctive linear presentation (fig 4a): $r=-0.73,(F=280, d f=1: 4 p<0.01)$. The four "ipsilesional" LBD patients (fig 4b) also show a significant linear pattern $r=-0.62$ ( $F=42 \cdot 1, \mathrm{df}=1: 4, \mathrm{p}<0.01$ ) whose bias is in the opposite direction to that which should be predicted. The remaining eight "contralesional" patients show a trend (fig 4c) in the expected direction but no significant linear pattern $(r=0.47)$.

Relationship between contralesional omissions and ipsilateral omissions

If, as suggested by Heilman et al and Mesulam, ${ }^{6}$ the right hemisphere contains bilateral attentional fields, then an association would be expected between ipsilesional and contralesional omissions. Gainotti et $\mathrm{al}^{1 \mathrm{O}}$ found no association between the number of omissions on the contralesional and ipsilateral sides in a drawing task undertaken by a group of right brain damage patients. Accordingly, they suggest that ipsilateral omissions may result from an overall lowering of general attention associated with severity of stroke, mental deterioration and age and affecting the whole visuo-spatial field. ${ }^{15}$

Their results on a drawing test are consistent with the results of our study of cancellation performance. In the RBD group $(n=14)$, the correlation between ipsilesional and contralesional omissions was not significant $(r=0.30)$. In the LBD group $(N=12)$ there was likewise no association between ipsilesional and contralesional omissions $(r=0 \cdot 16)$ for the group as a whole. No significant association was found in the eight contralesional patients $(r=$ 0.49 ) or the four ipsilesional patients ( $r=$ 0.04 ), although the former subgroup shows a suggestive trend.

Previous studies of tactile extinction ${ }^{29}$ have shown that non-specific factors such as old age, extent of brain lesion, and generalised mental deterioration may result in diminished attentional resources in both left and right brain damaged patients. ${ }^{30}$ Diffuse attentional impairment might therefore be expected to augment existing contralesional neglect, and in addition, produce omissions on the ipsilesional side of space which are unrelated to those errors in contralesional space. To check this hypothesis we examined the relationship between RBD omissions and the values on three other relevant variables; age, mental deterioration (Hodkinson Mental Scale), and extent of functional disability (Barthel Index). Although both the Barthel and the Hodkinson Mental test scores were not designed as specific measures of general attention they probably involve aspects of attentional impairment following stroke. The correlation between these two variables across both patients groups was significant $(r=0.59, p<0.01)$. Intercorrelations between lateralised omissions and performance on the Barthel and Hodkinson Mental test scores are shown in table 7. 
RBD omissions on the contralesional side are significantly related to performance on the Hodkinson Mental test (a screening measure of widespread mental deterioration) and performance on the Barthel Index (which reflects the overall severity of a patient's disability and by inference the extent of their stroke). Ipsilesional omissions are only significantly related to performance on the Hodkinson Test. Age did not correlate with the position of omissions on either side. In the LBD group, performance on the Barthel only was significantly related to contralesional omissions. Ipsilesional omissions did not relate to any of the non-specific variables.

These results favour the hypothesis put forward by Gainotti et al ${ }^{10}$ that ipsilesional omissions in the RBD group reflect generalised attentional impairment rather than a specific disorder of selective attention arising from the disruption of attentional neurons with bilateral receptive fields. The results also extend the findings of Gainotti et al by showing that nonspecific attentional impairments affect contralesional omissions equally in both left and right brain damaged groups.

Cancellation performance and extent of motor impairment

Previous studies have shown that about half of all survivors of stroke will have some motor impairment of the contralesional arm. ${ }^{31}$ To establish if there was any relationship between attentional impairment and hand functioning in our sample we looked at patients' performance on the Nine Hole Peg Test (NHPT), ${ }^{32}$ a test which had been administered at the same time as the SCT. The NHPT has the advantage of being simple, reliable, easy to administer and has been shown to relate to other tests of arm function and motor loss. It is a measure of manual dexterity which requires the patient to pick up nine ( $35 \mathrm{~mm}$ by $9 \mathrm{~mm}$ ) wooden pegs and place them in the corresponding holes on a square board. Results are expressed as the total time taken to place the nine pegs; scoring criteria are available for age matched controls. $^{33}$ Normative studies have shown that there is little or no difference between the performance of the dominant and non-dominant hands on this task. ${ }^{3233}$

To establish the incidence of motor impairment in our sample $(n=190)$, left and right hand performance on the NHPT was examined for all left $(n=98)$ and right $(n=92)$ brain damaged patients. The criterion used to establish the extent of motor impairment was the difference score in seconds between ipsilesional and contralesional hand performance. Converted to standardised scores, the values were then divided into hand difference scores within and beyond one standard deviation. Only twenty three patients $(12 \%)$ had difference scores beyond one standard deviation (>24 sec difference). These comprised 13 RBD (14\%) and 10 (10\%) LBD patients. Thus, $88 \%$ of the sample had interhand differences on the NHPT of less than 24 seconds. The mean (SD) score for both hands in this "no-difference" group was 18.4 seconds
$(=5 \cdot 8)$, well within the normal range for this age group ${ }^{32} 33$ and is probably due to the fact that most of the patients were seen several years after their stroke.

Performance within the attentionally impaired groups was then examined. In the LBD group, none of the 12 patients had a difference score greater than one standard deviation. In the RBD group ten of the 14 patients $(71 \%)$ had difference score values greater than the criterion. Differential intrahemispheric loci of lesions must account for this discrepancy between the groups; contralesional neglect appears to be strongly associated with contralesional motor impairment in our RBD sample.

\section{Discussion}

The "modal" model of the differential attentional capacity of the cerebral hemispheres, reviewed by Bisiach and Vallar, ${ }^{34}$ has the following structure. The right hemisphere is dominant for spatial attention in that it makes a larger overall contribution to the neural representation of egocentric space; it is capable of directing attention to any part of egocentric space, and has a slight bias towards contralateral space. The left hemisphere makes a smaller overall contribution, but is strongly biased towards contralateral space; at extreme right positions the left hemisphere takes precedence over the right and deploys greater attentional resources to those positions than does the right.

With a few qualifications, this "modal model" gives a reasonable fit to our data. The performance of the group with right hemisphere damage is (relatively) unproblematic. The patients show a strong linear relationship between omission rate and the lateral position of the targets. Omission errors increase from right to left positions, as predicted by a model in which performance is determined by the intrinsic attentional structure of the (unimpaired) left hemisphere. However, the slope of attentional "fall-off" in this group is probably overdetermined.

In addition to reflecting the "resting state" slope of left hemisphere attentional capacity, two other factors may serve to increase the slope yet further. First, the fact that all these patients used their right hand to perform the task will serve to activate the (undamaged) left hemisphere more than the (damaged) right hemisphere. $^{33536}$ This differential activation should itself magnify the intrinsic pattern of left hemisphere performance. Second, the use of the right hand acts as an intrinsic spatial cue to the right edge of the stimulus sheet. This spatio-motor cueing is another crucial aspect of task performance ${ }^{37}$ and provides an additional source for the right to left error gradient. Finally, an explicitly "hypokinetic/motor neglect" component ${ }^{38}$ may also play a role in modulating the final performance on the task.

The importance of these components ("activation" of the hemisphere that controls the hand used, and spatio-motor cueing by that 
hand) becomes critical when considering the performance of the group with left hemisphere damage. Like the patients with right hemisphere damage, these subjects also performed the task with their right hands; the extent and locus of their brain damage did not leave them with a contralesional hemiplegia that precluded the use of their (dominant) right (contralesional) hand. We accordingly find that a subgroup $(n=4)$ of patients with left hemisphere damage showed the same effect as the group with right hemisphere damage: there is a strong linear relationship between target position and error rate, with maximal omissions made in left space. If these patients had been using their (undamaged) right hemisphere to perform the task the relationship between lateral target positions and omission rate should have been the reverse of that found.

The presumption therefore must be this: the combined effects of right-sided spatio-motor cueing (the starting position of the right hand located at the right edge of the stimulus sheet) and left hemisphere activation (by use of the right hand) can conspire (in some patients) to overcome the bias of the normal (undamaged) right hemisphere. The overall error rate in these patients is outside normal limits, but the pattern of error suggests that the (damaged) left hemisphere is the primary determinant of their performance. That the undamaged right hemisphere plays some (albeit limited) role is suggested by the fact that the slope of the linear regression of errors for lateral target position is smaller than in the right brain damaged group. No member of this (atypical) left hemisphere group showed temporo-parietal damage on CT scan (see table 3); two scans were negative, one showed frontal damage, and one showed damage to the internal capsule.

The remaining subgroup of patients with left hemisphere damage $(n=8)$ shows a linear trend (that just fails to reach significance) in the direction predicted by the "modal model". They make minimal omissions on the left-most column of the task and maximal omissions on the rightmost column (see fig 4). The normal bias of the (undamaged) right hemisphere is thus operative in these patients. Nonetheless, the fact that the regression fails to reach an acceptable level of significance is revealing. These patients also used their right hands to perform the task. It may well be that the cueing and activation effects that arise from hand use have attenuated (but not abolished) the attentional bias of the right hemisphere. Half of these patients have CT scan evidence of damage to either temporal or parietal areas.

In conclusion, the "modal model" can (to a first approximation) accommodate most of our results. However, many theoretical models have not paid sufficient attention to the contribution of motor variables and visual field deficits to neglect performance. Although our previous studies $^{39}$ suggest that visual field cuts do not exacerbate neglect, we cannot rule out the possibility that in this study some of the performance differences between right and left brain damage patients were due in part to their visual field deficits; these defects were confined to the right hemisphere group. With respect to motor variables, Rizzolatti ${ }^{40}$ and Joanette and Brouchon $^{35}$ have highlighted the need to consider the initiation and elaboration of motor response in explaining neglect. The effects due to hand-use in particular ${ }^{3641}$ appear quite large and need to be taken into account in more detailed models of attentional asymmetries.

In retrospect, we realise that all patients in our sample who could have used both their hands to perform the cancellation task should have been asked to do so. That sample would include all 12 patients with left hemisphere damage, and at least four out of the 14 patients with right hemisphere damage. We had not anticipated that so many patients would be free of hemiplegia. Future studies of visual neglect assessed by motor response must explore the empirical and theoretical consequences of implicit cueing and of the fact that manual responses may in themselves be inherent determinants of attentional deployment.

This study was supported by the Medical Research Council and the Stroke Association.

1 De Renzi E. Disorders of space exploration and cognition. New York; J. Wiley, 1982.

2 Heilman K, Watson R, Valenstein E. Neglect and related disorders. In: Heilman KM, Valenstein E, eds. Clinical neuropsychology, 2nd ed. New York: OUP, 1985.

3 Kinsbourne M. Mechanisms of unilateral neglect. In: Jeannerod, $M$, ed. Neurophysiological and neuropsychological aspects of spatial neglect. New York; North Holland, 1987.

4 Reuter-Lorenz P, Kinsbourne M, Moscovitch M. Hemispheric control of spatial attention. Brain and Cognition 1990;12:240-66.

5 Heilman KW, Van Den Abell T. Right hemisphere dominance for mediating cerebral activation. Neuropsychologia inance for mediating

6 Mesulam MM. Attention, confusional states and neglect. In: Mesulam MM, ed. Principles of behavioural neurology. Philadelphia, Pa: FA Davis, 1985.

7 Feinberg TE, Haber LD, Stacy CB. Ipsilateral extinction in the hemineglect syndrome. Arch Neurol 1990;47:802-4.

8 De Renzi E, Gentillini M, Barbieri C. Auditory neglect. I Neurol Neurosurg Psychiatry 1989;52:613-7.

9 Weintraub S, Mesulam MM. Right cerebral dominance in spatial attention; further evidence based on ipsilateral neglect. Arch Neurol 1987;44:621-5.

10 Gainotti G, Giustolisi L, Nocentini U. Contralateral and ipsilateral disorders of visual attention in patients with unilateral brain damage. $\mathcal{f}$ Neurol Neurosurg Psychiatry 1990;53:422-6.

11 Albert ML. A simple test of visual neglect. Neurology 1973;23:658-64

12 Gainotti G, Messerli P, Tissot R. Qualitative analysis of unilateral spatial neglect in relation to laterality of cerebral lesions. F Neurol Neurosurg Psychiatry 1972;35:545-50.

13 Colombo A, De Renzi E, Faglioni P. The occurrence of visual neglect in patients with unilateral cerebral disease. Cortex 1976;12:221-31

14 Gainotti G, D'Erme P, De Bonis C. Components of visual attention disrupted in unilateral neglect. In: J Brown, ed. Neuropsychology of visual perception. London: LEA, 1989.

15 Gainotti G, D'Erme P, De Bonis C. Clinical aspects and mechanisms of unilateral spatial neglect. Rev Neurol 1989;145:626-34

16 Gainotti G, D'Erme P, Monteleone D, Silveri MC. Mechanisms of unilateral spatial neglect in relation to laterality nisms of unilateral spatial neglect in relation

17 Fullerton KJ, McSherry D, Stout RW. Albert's test; a neglected test of perceptual neglect. Lancet 1986; i:430-2.

18 Weintraub S, Mesulam MM. Visual hemispatial inattention; stimulus parameters and exploratory strategies. $\mathcal{f}$ Neurol Neurosurg Psychiatry 1988;51:1481-8.

19 Egelko S, Riley E, Simon D, Diller L, Ezrachi O. Unilateral spatial neglect; bias in contralateral search and fine spatial attention. Arch Clin Neurospychology 1988;3:213-25.

20 Halligan PW, Cockburn J, Wilson B. The behavioural assessment of visual neglect. Neuropsychological Rehabilitation 1991;1:5-32.

21 Halligan PW, Marshall JC, Wade DT. Visuospatial neglect; 
underlying factors and test sensitivity. Lancet 1989;ii: 908-11.

22 Bamford J, Sandercock P, Dennis M, Burn J, Warlow C. A prospective study of acute cerebrovascular disease in the community: the Oxfordshire Community Stroke Project: 1881-1986. I Neurol Neurosurg Psychiatry 1990;53 16-22.

23 Hatano $S$. Experience from a multicentre stroke register; a preliminary report. Bull WHO 1976;54:541-53.

24 Allen C. Predicting the outcome of acute stroke; a prognostic score. F Neurol Neurosurg Psychiatry 1984; 47:475-80

25 Hodkinson HM. Evaluation of a mental test score for assessment of mental impairment in the elderly. Age asseing 1972:1:233-8. impairment in the elderly. Age

26 Wade DT, Collin C. The Barthel ADL index: a standard measure of physical disability? Int Disabil Studies 1988;10:64-7.

27 Marshall JC, Halligan PW. Does the mid-sagittal plane play any privileged role in "left" neglect? Cognitive Neuropsychology 1989;6:403-22.

28 Friedman P. The star cancellation test in acute stroke Clinical Rehabilitation 1992;6:23-30

29 Gainotti G, Caltagirone C, Lemmo MA, Miceli G. Pattern of ipsilateral clinical extinction in brain damaged patients. Applied Neurophysiology 1975;38:115-25.

30 Gainotti G, De Bonis C, Daniele A, Caltagirone C. Contralateral and ipsilateral tactile extinctions in patients with right and left brain damage. Int $\mathcal{f}$ Neurosci
$1989 ; 45: 81-9$.

31 Parker VM, Wade DT, Langton Hewer R. Loss of arm function after stroke; measurement, frequency and recov- ery. Int Rehabil Med 1986;8:69-73

32 Mathiowetz V, Weber K, Kashman N, Volland G. Adult norms for the nine hole peg test. Occ Ther $\mathcal{F}$ Research 1985;5:24-37.

33 Heller A, Wade DT, Wood VA, Sunderland A, Langton Hewer R, Ward E. Arm function after stroke; measurement and recovery over the first three months. $\mathcal{f}$ Neuro Neurosurg Psychiatry 1987;50:714-9.

34 Bisiach E, Vallar G. Hemineglect in humans. In: Bollar F,

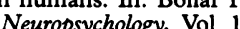
Amsterdam, Elsevier, 1988.

35 Joanette Y, Brouchon M, Gauthier L, Samson M. Pointing with left vs right hand in left visual field neglect. Neuropsychologia 1986;24:391-6.

36 Joanette Y, Brouchan M. Visual allesthesia in manual pointing; some evidence for a sensorimotor cerebral pointing; some evidence for a sensorimotor cere
organization. Brain and Cognition 1984;3:152-65.

37 Halligan PW, Manning L, Marshall JC. Hemispheric activation vs spatio-motor cuing in visual neglect; a case study. Neuropsychologia 1991;29:165-76.

38 Bisiach E. Geminiani G, Berti A, Rusconi M. Perceptual and premotor factors in unilateral neglect. Neurology 1990;40:1278-81.

39 Halligan PW, Marshall JC, Wade DT. Do visual field deficits exacerbate visuo-spatial neglect? $f$ Neurol Neurosurg Psychiatry 1990;53:487-91.

40 Rizzolatti G, Gallese V. Mechanisms and theories of spatial neglect. In: Boller F, Grafman J, eds. Handbook of neuropsychology, Vol 1. Amsterdam: Elsevier, 1988.

neuropsychology, Vol 1. Amsterdam: Elsevier, 1988 .
41 Halligan PW, Marshall JC. Laterality of motor response in visuo-spatial neglect; a case study. Neuropsychologia 1989;27:1301-7. 